\title{
Bridging the Divide: The Role of Sport Events in Contributing to Social Development Between Disparate Communities
}

\author{
Nico Schulenkorf ${ }^{1}$
}

Received: 26.08.2010

\begin{abstract}
${ }^{1}$ Lecturer, Sport and Event Management, School of Sport \& Recreation, Auckland University of Technology, Private Bag 92006, Auckland 1142, New Zealand, Phone: +64 99219999 ext. 7311, e-mail: nico.schulenkorf@aut.ac.nz
\end{abstract}

Supervisor: Dr. Deborah Edwards (Principal Supervisor)

Assoc. Prof. Bruce Hayllar (Secondary Supervisor)

Institution awarding the Ph. D. Degree: University of Technology, Sydney (UTS) / Australia

Date of defence: $26^{\text {th }}$ November 2009

(c) 2010 International University College. All rights reserved

Citation: Schulenkorf, N. (2010) Bridging the Divide: The Role of Sport Events in Contributing to Social Development Between Disparate Communities. Doctoral dissertation summary. European Journal of Tourism Research 3(2), pp. 127-131

\section{Background I Statement of the problem}

Sport events offer valuable experiences to participants, supporters, and other stakeholders while its impacts are of significant economical, political, social and psychological importance. From a social perspective, sport has been described as a language which all people in the world understand and speak and which is able to emotionally unite groups (Dyreson 2003). However, despite the increased recognition and use of sport and event projects as important contributors to the social fabric of multicultural societies, evaluations of inter-community sport events for the purposes of social development have largely been overlooked. Most 'evidence' in the event area is based on anecdotes and symbolic gestures suggesting that sport events can contribute to reconciliation and intergroup development. To fill this gap, this thesis empirically investigates the ability of inter-community sport events to contribute to social development in divided societies.

Research question and objectives of the dissertation

Research question

What is the role of inter-community sport events in contributing to social development between disparate groups?

Objectives

1. Understand the socio-cultural experiences that arise from intercommunity sport events.

2. Investigate how inter-community events impact on people's social identities and group categorisations.

3. Identify the roles and responsibilities of a change agent in facilitating community development projects. 
Bridging the Divide: The Role of Sport Events in Contributing to Social Development Between Disparate Communities. Doctoral dissertation summary.

4. Understand how positive relations can be sustained and leveraged beyond the event.

5. Identify the implications for social development through sport events resulting from this research.

\section{Methodology}

This research is located within an interpretive paradigm informed by qualitative methods an approach to research that portrays a world in which reality is viewed as socially constructed, complex, and ever changing (Denzin and Lincoln 2005; Glesne 1999). Interpretive studies aim to understand the context of a case or a phenomenon through the meanings that people assign to it. As expert knowledge is often situated in local cultures and imbedded in interactional sites (Denzin and Lincoln 2005; Crotty 1998), qualitative researchers interact and talk with participants about their perceptions and take an 'inside view' from participants' perspectives.

Empirical research was conducted around two inter-community sport events in war-torn Sri Lanka, where data was collected from disparate Sinhalese, Tamil and Muslim communities and international organisers through focus groups, in-depth interviews and participant observation. Through careful interpretation and analysis of people's experiences, feelings, ideas and concerns new knowledge was created.

\section{Results}

The data revealed that people experience both positive and negative socio-cultural impacts at events, which influence the stock of social capital available to communities. On the positive side opportunities to socialise, interact and cooperate with 'others' contribute to cultural learning, feelings of increased comfort and trust, and the establishment of networks. On the negative side, social development can be undermined by attitudinal differences and management tensions. Different experiences were found to influence the way people see and categorise 'others' in group identity terms. When positive experiences dominate and social connections are enabled, the creation of multiple inclusive social identities can be achieved along national and organisational lines, common interests, and imagined factors. This supports the claim that inter-community events can contribute to inclusive social change and a sense of togetherness and belonging.

It was further found that international 'change agents' are required to find the right balance between guiding sport event projects and allowing local communities to engage and participate. They need to be innovative and responsible advocates for social capital and capacity building by facilitating the creation of trust and networks between local groups. Over time, change agents are required to gradually transfer event responsibilities and control to assist the communities in developing resources and achieving local empowerment. Furthermore, there is a need to focus on a strategic and cooperative approach in order to sustain, grow and leverage the benefits of sport events. Pre event, the change agent and communities are encouraged to engage in 'bonding sessions' to get to know each other, and to decide on event leveraging strategies. During the event, ethnically mixed team sport activities and event-related socio-cultural experiences allow participants and spectators to achieve 'togetherness in diversity'. Post event, a combination of community partnerships, regular sport programs and 'highlight events' can secure ongoing opportunities for both bonding and bridging social capital.

\section{Theoretical contributions and practical applications}

A major contribution of this research is a greater understanding of the experiences resulting from inter-community sport events between disparate groups in a developing world context. In-depth interviews identified various experiences under eight underlying themes, namely Socialising, Trust, Reciprocity, Networks, Learning, Cultural Celebration, Attitudes, and Management Tensions. From a practical perspective, these experiences need to be considered when planning and managing events with the final 
aim of enhancing intergroup relations and social capital in divided societies.

A second major contribution is the identification of how inter-community events impact on people's social identities and group categorisations. The study revealed that within a supportive sport event environment, disparate groups can actively create and experience inclusive social identities along national and organisational lines, common interests and imagined factors. These social identities can be experienced simultaneously, and people are able to bond with 'others' through the most suitable inclusive identity prevailing at a certain time. However, neither of the contact categorisation models available in the literature provide a suitable framework for multiple and simultaneously experienced identities. This thesis therefore calls for further research to be conducted on the design of inclusive multiple social identity models and frameworks for improving intergroup contact and relations.

A third contribution of this research is the identification of specific roles and responsibilities an international change agent holds at inter-community sport event development projects. Respondents highlighted that development towards community participation, trust building, establishment of networks, leadership, social responsibility, resource development, innovation, and long-term planning are important elements of a change agent's work. The identification of these roles and responsibilities extend the academic literature on the management of sport-for-development projects, in which there has been relatively little empirical work done. Further, these findings have practical implications for an inclusive and responsible management style of change agents, event organisers and sport agencies operating in a developing world context.

An additional contribution of this research is the deeper understanding of how sport event benefits can be sustained, grown and leveraged beyond event borders. Strategies identified to maximise social event benefits include the staging of pre-event 'bonding sessions'; a focus on ethnically mixed team sports; the provision of social opportunities around the main event; the combination of special events with regular sport programs and exchanges; a focus on youth as catalysts; and the leveraging of event benefits. By implementing these strategies, events can advance social capital, social change and local capacity building, which has flow-on effects to the community at large. The findings extend the academic literature on strategic event planning and event leverage (O'Brien 2007; Chalip 2006, 2004), as they provide a focus on community event leverage for social purposes - an area which has thus far received limited empirical research.

Finally, a process oriented framework for social inter-community event management was developed in light of this study. Its aim is to assist communities, change agents and event managers to plan for positive social outcomes and sustainable community development. The SICEM framework fills a gap in the literature, as currently there are no specific frameworks available which describe and visualise the social processes of (sport) event management for social development. Finally, on a philosophical level, this research introduced the 'Model for Community Empowerment', which can underpin 'bottomup' community projects that aim to achieve sustainable social development in the developing world.

\section{Content of the dissertation}

Abstract of chapter one: Sport Events for Social Development

Chapter One provides a background to the research and introduces the research question and objectives. It provides a justification for analysing the strategic means by which to capitalise on sport and intergroup celebration in order to contribute to social development in divided societies. The theories and concepts underpinning this research, its delimitations, scope and expected contributions are highlighted. 
Bridging the Divide: The Role of Sport Events in Contributing to Social Development Between Disparate Communities. Doctoral dissertation summary.

Abstract of chapter two: Literature Review

This chapter provides a review of the literature relevant to the development of this research. It begins with a discussion of the concepts, benefits and challenges of community participation for social development, and in particular the building of social capital. The social psychology of intergroup relations is then presented, which explains how people in a group perceive and behave towards people in other groups. The emphasis here is on the concept of intergroup conflict and the different approaches for reducing social distance between groups. Attention is then directed to Social Identity Theory (SIT), which is discussed with a strong focus on the four categorisation models for mediating the effects of intergroup contact particularly for large-scale groups such as ethnic communities. The literature review concludes by discussing the impacts of events, including a focus on the sports factor in events and the socio-cultural impacts of community celebrations.

\section{Abstract of chapter three: Methodology}

The chapter comprises two interrelated sections: research methodology, and research methods. The methodology section provides the theoretical and philosophical concepts that underpin this interpretive research and outlines the research design which is based on a case study approach. The methods section details the three qualitative methods used for data collection: focus groups, participant observation and semi-structured in-depth interviews. The chapter further describes the thematic analysis process, acknowledges potential bias, and highlights the ethical considerations undertaken to ensure that no harm came to the participants and researcher.

\section{Abstract of chapter four: Social Context}

This chapter provides the social context of the particular case that is examined in this research - Sri Lanka. It presents a geographic and demographic overview of the country, its historical development, its prevailing problems with violence and terrorism, and the current socio-political circumstances on the island. Furthermore, the chapter describes the change agent A.G.S.E.P. and summarises the two intercommunity sport events analysed for this research: the International Run for Peace (IR4P) in Sri Lanka's capital Colombo and the Intercultural Sports Meeting (ISM) in the rural western Sri Lankan community Nattandiya.

\section{Abstract of chapter five: Findings}

This chapter presents the findings from the data collection and reports them in accordance with the research question and objectives. The chapter begins by outlining the findings on socio-cultural event impacts and experiences. Then, the research participants' experiences of intergroup relations, social identities and group categorisations are presented. This is followed by an outline of the specific roles and responsibilities of the change agent in facilitating community development projects. The chapter concludes by presenting the suggested strategies for sustaining and leveraging event benefits beyond event borders.

\section{Abstract of chapter six: Discussion and Conclusion}

Chapter Six discusses the findings of this study in relation to previous research and theories in the areas of Community Participation, Social Capital, Intergroup Relations, SIT, and Event Impacts. This final chapter provides an overview of what has been achieved in respect to answering the overriding research question. In particular, the potential of inter-community events in enhancing social capital, social change and capacity building is discussed. In light of this research the Strategic Inter-Community Event Management (SICEM) framework is presented, which combines findings of the empirical research with the different literature areas investigated. Finally, the theoretical contributions and practical implications of this research are highlighted, and suggestions for further research are proposed based on the developments made in this thesis.

The thesis concludes that inter-community sport events can be used as vehicles, catalysts and boosters for social development between disparate communities. They have 
the power to advance social capital, foster inclusive socio-cultural change and add to local capacity building. While inter-community sport events should be encouraged and expanded as part of an active social development process, it is too much to expect sport events to have a major impact on overall intergroup relations in the absence of a political settlement in divided societies.
However, when integrated within a larger agenda of social, educational and political support and inclusive reforms, intercommunity sport events can make a modest contribution to resolving conflict and bridging divides between disparate communities. 